\title{
Hepatitis and Lupus-Like Syndrome during Infliximab Therapy for Psoriasis
}

\author{
Hassan Riad Samya Abu Shaikha Hamda Al Ansari Khalifa Al Naama \\ Hussein Al Sada Mariam Al Mansoori \\ Hamad Medical Corporation, Doha, Qatar
}

\section{Key Words}

Hepatitis · Lupus-like syndrome $\cdot$ Infliximab therapy $\cdot$ Psoriasis

\begin{abstract}
Biologics are very useful medications that changed the lives of many patients in the last decade. However, we still do not know about the long-term side effects of these drugs. Infliximab is an anti-TNF chimeric antibody widely used and approved for the treatment of many diseases. Lupus-like syndrome and hepatitis are among the uncommon side effects of infliximab. Most of the written literature was published for cases of rheumatology and gastroenterology. We report here a case of both hepatitis and lupus-like syndrome that occurred sequentially in the same patient and compare our finding with two case reports of the same side effects, drug and disease.

(C) 2013 S. Karger AG, Basel
\end{abstract}

\section{Introduction}

The side effects of biologics differ both qualitatively and quantitatively among different diseases. Psoriasis was treated with biologics for the last decade, and several post-marketing reports were published on their side effects that infrequently include lupus and hepatitis.

Systemic lupus erythematosus (SLE) is an autoimmune disease diagnosed by the presence of four out of eleven criteria of the American Rheumatism Association (ARA) for the diagnosis of the disease. Drug-induced lupus erythematosus is less well defined than SLE; it is necessary for the diagnosis of drug-induced lupus erythematosus to temporarily use a drug in patients who have no prior history of the disorder and to check for disappearance of the disorder after discontinuation of the drug [1]. Lupus-like syndrome attributable to drug

Prof. Hassan Riad

Senior Consultant at Hamad Medical Corporation

POB 3050

Doha (Qatar)

E-Mail hssnrd@yahoo.com 
intake is an autoimmune disease which occurs after the use of a drug that induces at least one serological marker and one non-serological marker of lupus in patients who have not suffered from the disease before and who do not fulfill the minimal ARA criteria for the diagnosis of SLE [2].

Lupus-like syndrome has been reported with the use of TNF antagonists as well as other biologics. Infliximab has also been reported to induce lupus-like syndrome in patients with rheumatoid arthritis and inflammatory bowel disease and rarely in psoriatic patients.

Excluding reactivation of infective hepatitis, the clinical presentations of hepatitis encountered during therapy with infliximab in different disorders are variable. Liver biopsies and serological profiles of different cases reported showed pictures of either toxic or autoimmune hepatitis (AIH). The mechanism of liver injury by infliximab is still unknown; it might be idiosyncratic or autoimmune [3].

The occurrence of both lupus-like syndrome and hepatitis with infliximab therapy in the same patient is extremely rare. We report here a case of psoriasis that experienced both side effects under infliximab therapy.

\section{Case Report}

A 23-year-old female presented with generalized plaque psoriasis of 10 years duration. She was married and using an intrauterine device for contraception. Her quality of life was severely affected (dermatology life quality index $=16$ ), body surface area involvement was $17 \%$, and her body mass index was 28 (overweight). Scalp, nails and flexures were involved, while the palms, soles and joints were spared at that time. The patient had received different systemic and topical conventional therapeutic modalities including methotrexate (cumulative dose of $430 \mathrm{mg}$ ) with variable responses. She had no history of alcohol consumption or smoking and no history of other drugs that may exacerbate or induce hepatitis or lupus erythematosus. Infliximab was initiated in February 2010 at a dose of $5 \mathrm{mg} / \mathrm{kg}$ per infusion session on 0,2 and 6 weeks and then every 8 weeks. The patient responded nicely to therapy, but after the fifth injection session in July 2010, she noticed dark urine and lethargy. Liver function tests showed a marked elevation in liver enzymes and total bilirubin. The level of immunoglobulin $\mathrm{G}$ was $2,100 \mathrm{mg} / \mathrm{dl}$, i.e. about $130 \%$ of the upper limit (normal 700$1,600 \mathrm{mg} / \mathrm{dl}$ ); other immunoglobulins (IgM and IgA) showed normal findings, while antinuclear antibodies (ANAs) turned positive with a titer of 1:320 (speckled). The laboratory results are displayed in table 1 . Screening for viral hepatitis (A, B, C and E) showed negative result. Anti-microsomal antibodies, anti-mitochondrial antibodies, anti-soluble liver antigen, anti-smooth-muscle antibody, anti-liver-kidney microsomal antibodies, prothrombin time and international normalized ratio were all within normal ranges or negative. Anti-soluble liver antigen/liver-pancreas antibodies and pANCA were not done. Liver ultrasound was normal, showing normal hepatic size and echogenicity as well as normal gallbladder and bile ducts.

The patient did not give consent for liver biopsy. She was diagnosed as suffering from $\mathrm{AIH}$ and given corticosteroids; the following dose of infliximab was suspended. Her liver function test improved dramatically within the first 4 weeks. She was given etanercept $50 \mathrm{mg}$ bi-weekly for 12 weeks, which unfortunately showed primary lack of response and injection site hypersensitivity. Her liver function test returned to baseline after 2 months. Under care by a hepatologist and with consent of the patient, infliximab therapy was resumed with great caution due to flare-up of the skin condition. 
The patient received three re-initiation doses with good response and no changes in liver function tests. This was followed by five doses over a year. In January 2012 she was admitted to hospital with fever $\left(39^{\circ} \mathrm{C}\right)$, severe arthralgia, myalgia, lethargy and depression. Erythrocyte sedimentation rate and C-reactive protein were highly elevated. On examination there were severe symmetrical peripheral arthritis lesions with swelling, effusion and mobility problems involving the knees, elbows and proximal small joints of both hands and feet. There was no axial joint involvement. There was an ANA titer of 1:1,280 (homogenous), positive anti-Sm, positive anti-histone antibodies, negative anti-double-stranded DNA (antidsDNA) antibodies, negative rheumatoid factor and normal serum complement. No malar rash, photosensitivity, mouth ulceration, visceral organ involvement, serositis, renal involvement, proteinuria, cytopenia or any other manifestations of lupus erythematosus were observed. The patient was diagnosed as having lupus-like syndrome due to infliximab therapy. Infliximab was eventually discontinued. The condition was controlled by corticosteroids, leflunomide and azathioprine. Her general condition and arthritis improved within 2 months, liver function tests remained within normal limits, and anti-Sm and anti-histone antibodies returned to normal values. Her ANA titer went down to 1:160 (homogenous); 24 months later the condition remained stable with no relapse or recurrence of drug-related symptoms (table 1). Corticosteroids were stopped 7 months later; she is maintained on sulfasalazine, hydroxychloroquine and ustekinumab injections. The main complaint of the patient during the latest period was worsening of the joint condition, especially in the small joints of the hands that started to show erosive arthritis and minor deformities.

\section{Discussion}

Anti-TNF biologics are the latest group of medications responsible for induction of the so-called lupus-like syndrome. It is still unclear whether this drug-induced lupus-like syndrome follows a uniform pattern for the same medication or in the same disease. Autoantibody production occurs quite frequently with anti-TNF therapy, some studies showing a high percentage of conversion from $12 \%$ ANA-positive at baseline to $72 \%$ ANA-positive after 22 weeks of infliximab therapy [4]. However, lupus-like syndrome occurred in a relative low percentage of these patients $(0.22 \%)$. Only about 140 cases with lupus-like syndrome have been reported after millions of anti-TNF and other biologics injections all over the world [5].

Only three case reports have been published on the incidence of combined lupus-like syndrome and hepatitis in the same patient as a side effect of the use of biologics, two of them with infliximab use in psoriasis [6, 7] and one with infliximab in ulcerative colitis [8]. Our case was diagnosed as lupus-like syndrome due to elevation of ANA at 1:1,280, homogenous pattern, positive anti-Sm antibodies, positive anti-histone antibodies and bilateral arthritis in conjunction with high fever and constitutional manifestations. Some of these features were also encountered in the other two psoriasis cases [6, 7] (table 2). Unlike our case, those two cases showed skin manifestations such as malar erythema, photosensitivity and mouth ulcer. They also showed transient elevation in anti-dsDNA antibodies, which in our case remained negative despite the course of the disease.

The main difference between the other two cases and ours is the simultaneous occurrence of hepatitis and lupus-like syndrome in the former, while in the latter hepatitis occurred first and lupus-like syndrome followed more than 1 year later. In common between the three cases are female gender, history of methotrexate therapy, hepatitis after the fifth injection, transient elevation of alanine aminotransferase (ALT) and aspartate aminotrans- 
ferase (AST) levels (ALT more than AST), transient high elevation of ANAs, severe arthritis and depression.

SLE may be associated with AIH. Lupus-associated hepatitis has been challenging, as there are similarities between the clinical features and the laboratory findings in both these entities. The two entities can co-exist; this is referred to as AIH-SLE overlap syndrome. Liver biopsy may be distinctive between SLE and AIH; periportal necrosis associated with lobular activity, rosetting of liver cells or dense lymphoid infiltrates are prominent in AIH, whereas in SLE, inflammation is usually lobular and occasionally periportal, with paucity of lymphocytic infiltrate [9].

Cases of hepatitis with infliximab therapy in psoriasis are infrequent, though a clear warning was added to the drug leaflet in 2004. Those cases share elevated transaminases, cholestasis, high ANA positivity and resolution after drug interruption. Some cases had a cofactor for liver injury such as alcohol consumption or methotrexate administration.

Menter et al. [10] in 2007 reported in a controlled study over 1 year for different dose regimens that $4.9 \%$ of patients developed an elevation in ALT and 3.1\% developed an elevation in AST, and at any time during that study, $1.7 \%$ of patients developed ALT values more than 8 times the upper limit of normal (ULN).

The cause of infliximab-induced liver cell injury is still unknown. The types of hepatic injury vary from acute liver failure to less severe forms as cholestasis, reactivation of hepatitis B and autoimmune hepatitis [6]. Our case was diagnosed as AIH. Infliximab was resumed in this patient after transient hepatic injury for 8 more infusions due to the severity of the psoriatic lesions and failure to respond to another anti-TNF (etanercept). No laboratory abnormality was noticed that indicated recurrence of hepatic injury even when she developed lupus-like syndrome; liver disorder did not recur. Positive re-challenge after drug-induced liver injury is not recommended, especially if the transaminase level exceeds 5 -fold the upper normal limit, and may lead to recurrence of the condition and serious complications. Under limited circumstances, when the benefit of the drug is remarkable and the attribution of the drug to liver injury is uncertain, re-introduction of the drug with strict precaution can be an option; in our patient, it was the only way to control her severe skin condition at that time.

Methotrexate therapy has a definite hepatic toxic effect, though it is unpredictable and better avoided in such patients. To control psoriasis and psoriatic arthritis, another anti-TNF (etanercept) was added because of difference in molecular composition and lack of crossreactivity. However, we should also keep in mind before switching drugs that biologics within the same group may have the same side effects. Other anti-TNFs have also been reported to induce hepatitis and lupus-like syndrome. Non-TNF blockers such as ustekinumab were helpful in this patient, in addition to other adjuvant medications to control here severe joint problems.

In conclusion, we present a case of rare side effects of infliximab in a psoriatic patient. We are glad that the patient overcame these side effects and are doing our best to follow up the case. 
Riad et al.: Hepatitis and Lupus-Like Syndrome during Infliximab Therapy for Psoriasis

\section{References}

1 Dalle Vedove C, Simon JC, Girolomoni G: Drug-induced lupus erythematosus with emphasis on skin manifestations and the role of anti-TNF $\alpha$ agents. J Dtsch Dermatol Ges 2012;10:889-897.

2 Wetter DA, Davis MD: Lupus-like syndrome attributable to anti-tumor necrosis factor alpha therapy in 14 patients during an 8-year period at Mayo Clinic. Mayo Clin Proc 2009;84:979-984.

3 Ghabril M, Bonkovsky HL, Kum C, Davern T, Hayashi PH, Kleiner DE, Serrano J, Rochon J, Fontana RJ, Bonacini M; US Drug-Induced Liver Injury Network: Liver injury from tumor necrosis factor- $\alpha$ antagonists: analysis of thirty-four cases. Clin Gastroenterol Hepatol 2013;11:558-564.e3.

4 Poulalhon N, Begon E, Lebbé C, Lioté F, Lahfa M, Bengoufa D, Morel P, Dubertret L, Bachelez H: A follow-up study in 28 patients treated with infliximab for severe recalcitrant psoriasis: evidence for efficacy and high incidence of biological autoimmunity. Br J Dermatol 2007;156:329-336.

5 Perez-Alvarez R, Pérez-de-Lis M, Ramos-Casals M; BIOGEAS study group: Biologics-induced autoimmune diseases. Curr Opin Rheumatol 2013;25:56-64.

6 Poulin Y, Thérien G: Drug-induced hepatitis and lupus during infliximab treatment for psoriasis: case report and literature review. J Cutan Med Surg 2010;14:100-104.

7 Dang LJ, Lubel JS, Gunatheesan S, Hosking P, Su J: Drug-induced lupus and autoimmune hepatitis secondary to infliximab for psoriasis. Australas J Dermatol DOI: 10.1111/ajd.12054.

8 Marques M, Magro F, Cardoso H, Carneiro F, Portugal R, Lopes J, Costa Santos C: Infliximab-induced lupuslike syndrome associated with autoimmune hepatitis. Inflamm Bowel Dis 2008;14:723-725.

9 Koshy JM, John M: Autoimmune hepatitis - SLE overlap syndrome. J Assoc Physicians India 2012;60:59-60.

10 Menter A, Feldman SR, Weinstein GD, Papp K, Evans R, Guzzo C, Li S, Dooley LT, Arnold C, Gottlieb AB: A randomized comparison of continuous vs. intermittent infliximab maintenance regimens over 1 year in the treatment of moderate-to-severe plaque psoriasis. J Am Acad Dermatol 2007;56:31.e1-31.e15.

Table 1. Laboratory values of the patient on a timeline

\begin{tabular}{|c|c|c|c|c|c|c|c|}
\hline & $\begin{array}{l}\text { February } 2010 \\
\text { (initiation of } \\
\text { infliximab) }\end{array}$ & $\begin{array}{l}\text { July } 2010 \\
\text { (hepatitis, 5th } \\
\text { injection of } \\
\text { infliximab) }\end{array}$ & $\begin{array}{l}\text { November } 2010 \\
\text { (re-initiation of } \\
\text { infliximab) }\end{array}$ & $\begin{array}{l}\text { November } 2011 \\
\text { (last dose of } \\
\text { infliximab) }\end{array}$ & $\begin{array}{l}\text { January } 2012 \\
\text { (lupus-like } \\
\text { syndrome) }\end{array}$ & $\begin{array}{l}\text { July } 2012 \\
\text { (follow-up) }\end{array}$ & $\begin{array}{l}\text { July } 2013 \\
\text { (follow-up) }\end{array}$ \\
\hline $\operatorname{ALT}(0-30 \mathrm{U} / \mathrm{l})$ & 11 & 645 & 14 & 11 & 18 & 15 & 16 \\
\hline AST $(0-31 \mathrm{U} / \mathrm{l})$ & 14 & 394 & 12 & 19 & 15 & 14 & 18 \\
\hline ALP (45-129 U/l) & 92 & 94 & 99 & 53 & 43 & 87 & 90 \\
\hline GGT $(7-32 \mathrm{U} / \mathrm{l})$ & 10 & 32 & 33 & 25 & 26 & 31 & 33 \\
\hline Bilirubin $(3.5-24 \mu \mathrm{mol} / \mathrm{l})$ & 7 & 65 & 6 & 8 & 4 & 7 & 4 \\
\hline ANAs pattern & negative & $\begin{array}{l}\text { 1:320 } \\
\text { (speckled) }\end{array}$ & $\begin{array}{l}\text { 1:320 } \\
\text { (speckled) }\end{array}$ & $\begin{array}{l}\text { 1:1,280 } \\
\text { (homogenous) }\end{array}$ & $\begin{array}{l}1: 1,280 \\
\text { (homogenous) }\end{array}$ & $\begin{array}{l}\text { 1:160 } \\
\text { (homogenous) }\end{array}$ & $\begin{array}{l}\text { 1:160 } \\
\text { (homogenous) }\end{array}$ \\
\hline Histone antibody & negative & negative & negative & negative & positive & negative & negative \\
\hline Anti-native DNA & negative & negative & negative & negative & negative & negative & negative \\
\hline Anti-Sm antibody & negative & negative & negative & negative & positive & negative & negative \\
\hline
\end{tabular}

ALP = Alkaline phosphatase; GGT = gamma-glutamyl transferase. 


\section{Case Reports in Dermatology}

\begin{tabular}{l|l}
\hline Case Rep Dermatol 2013;5:219-224 \\
\hline DOI: 10.1159/000354593 & $\begin{array}{l}\text { C 2013 S. Karger AG, Basel } \\
\text { www.karger.com/cde }\end{array}$ \\
\hline
\end{tabular}

Riad et al.: Hepatitis and Lupus-Like Syndrome during Infliximab Therapy for Psoriasis

Table 2. The three psoriasis cases with hepatitis and lupus-like syndrome due to infliximab use

\begin{tabular}{|c|c|c|c|}
\hline & Our case & Poulin and Thérien, 2010 [6] & Dang et al., 2013 [7] \\
\hline Age (years), race & 23, Caucasian & 40, Caucasian & 47, Asian \\
\hline Sex & female & female & female \\
\hline Duration & $\overline{10 \text { years }}$ & long-standing (unknown) & $\overline{9 \text { years }}$ \\
\hline Body mass index & 28 & 22.1 & unknown \\
\hline Severity of psoriasis (BSA) & $17 \%$ & unknown & $25 \%$ \\
\hline Past medications & $\begin{array}{l}\text { cyclosporine, methotrexate } \\
\text { dose } 430 \mathrm{mg}\end{array}$ & $\begin{array}{l}\text { cyclosporine, methotrexate } \\
\text { dose } 1,260 \mathrm{mg}\end{array}$ & $\begin{array}{l}\text { cyclosporine, NB-UVB, } \\
\text { methotrexate, retinoid, } \\
\text { ustekinumab }\end{array}$ \\
\hline Baseline hepatic enzymes & no history of elevation & $\begin{array}{l}\text { elevated shortly on methotrexate, } \\
\text { then back to baseline }\end{array}$ & no history of elevation \\
\hline Concomitant drugs & no & $\begin{array}{l}\text { oral contraceptive pills and other } \\
\text { drugs }\end{array}$ & $\begin{array}{l}\text { methotrexate } 2.5-5 \mathrm{mg} \\
\text { per week }\end{array}$ \\
\hline Infliximab injections before liver injury & $\underline{5}$ & $\underline{5}$ & $\underline{5}$ \\
\hline $\begin{array}{l}\text { Infliximab injections before lupus-like } \\
\text { syndrome }\end{array}$ & 13 & 5 & 5 \\
\hline Liver lab & $\begin{array}{l}\text { elevated ALT and AST, bilirubin, } \\
\text { IgG }\end{array}$ & elevated ALT and AST & elevated ALT and AST \\
\hline Liver biopsy & not done & $\mathrm{AIH}$ & $\mathrm{AIH}$ \\
\hline Arthritis prior to lupus-like syndrome & & yes & yes \\
\hline Lupus-like symptoms & fever, arthritis, arthralgia, myalgia & malar rash, arthritis, arthralgia & $\begin{array}{l}\text { photosensitivity, mouth } \\
\text { ulcers, arthritis }\end{array}$ \\
\hline Lupus serology & $\begin{array}{l}\text { high ANA } \\
\text { positive }\end{array}$ & high ANA, dsDNA positive & high ANA \\
\hline Other associated symptoms & depression & depression & depression \\
\hline
\end{tabular}

Common findings are underlined. BSA = Body surface area; NB-UVB = narrow-band ultraviolet B phototherapy. 